\title{
Alterations to biological soil crusts with alpine meadow retrogressive succession affect seeds germination of three plant species
}

\author{
LI Yi-kang1,2 iD http://orcid.org/oooo-0oo3-4772-3233; e-mail: liyikang501@163.com \\ OUYANG Jing-zheng4 (iD http://orcid.org/oooo-0002-7431-2694; e-mail: oyjztt@163.com \\ LIN Li1 (D http:// orcid.org/oooo-0oo3-2531-0032; e-mail: hanxiao_200o_oo@126.com \\ XU Xing-liang3 iDhttp://orcid.org/oooo-0oo3-2869-4932; e-mail: xuxingl@hotmail.com \\ ZHANG Fa-wei',2 iD http://orcid.org/oooo-00o3-0693-7956; e-mail: flingzhang@gmail.com \\ DU Yan-gong1 iD http://orcid.org/oooo-ooo2-3324-2124; e-mail: ygdu@nwipb.cas.cn \\ LIU Shu-li1,2 (D http://orcid.org/oooo-ooo1-8448-2753; e-mail: liushulio203@163.com \\ CAO Guang-min' (D http://orcid.org/oooo-ooo1-6115-9347; e-mail: caogm@nwipb.cas.cn

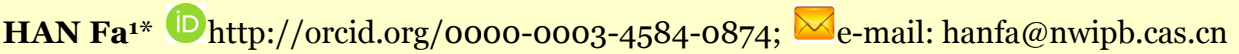 \\ * Corresponding author \\ 1 Key Laboratory of Adaptation and Evolution of Plateau Biota, Northwest Institute of Plateau Biology, Chinese \\ Academy of Sciences, Xining 810oo1, China \\ 2 University of Chinese Academy of Sciences, Beijing 100049, China \\ 3 Institute of Geographic Sciences \& Natural Resources Research, the Chinese Academy of Sciences, Beijing 10o101, China \\ 4 Liancheng National Nature Reserve of Gansu Province, Yongdeng Country 730ooo, China
}

Citation: Li YK, Ouyang JZ, Lin L, et al. (2016) Alterations to biological soil crusts with alpine meadow retrogressive succession affect seeds germination of three plant species. Journal of Mountain Science 13(11). DOI: 10.1007/s11629-016-3917-3

(C) Science Press and Institute of Mountain Hazards and Environment, CAS and Springer-Verlag Berlin Heidelberg 2016

\begin{abstract}
Biological soil crusts (BSCs) are the important components of alpine meadow ecosystems. The extent and morphology of BSCs vary greatly with alpine meadow retrogressive succession due to grazing pressure. There is significant interest in impacts of crust composition on plant seed germination, especially in (semi-) arid environments. However, little is known about the influences of BSCs, and their associations with alpine meadow succession, on germination of typical alpine meadow vascular plant species. In a full factorial common-garden
\end{abstract}

\section{Received: 1 March 2016}

Revised: 3 May 2016

Accepted: 22 July 2016 experiment, we studied effects of: (1) crust type, (2) seed position, and (3) surface texture on seed germination. We chose three typical alpine meadow plant species (i.e. Poa pratensis, Tibetia himalaica and Potentillen nivea), which belonged to different functional groups (graminoids, legumes, and forbs) and play important roles in all alpine meadow succession stages. Crust type and seed position influenced seed germination, and the inhibitory effects of BSCs depended on the crust type and seed species tested. The major factors influencing seed germination were BSC type, seed position, soil texture, and the interactions between BSC type and seed position; species and seed position; species and 
surface texture; and species, crust type, and surface texture. Cyanobacteria crust significantly inhibited germination of all seeds. Seed position also had a significant effect on seed germination $(p<0.001)$. Fewer seedlings germinated on the surface than below the surface, this was especially true for $P$. nivea. seeds within cyanobacteria and lichen crusts. Only germination rates of $T$. himalaica on the soil surface were significantly correlated with plant occurrence frequency within the alpine meadow community. The poor correlation for the other two species is possibly that they are perennials. Our results clearly demonstrated that BSCs can be biological filters during seed germination, depending on the BSC succession stage. Through their influences on seed germination, BSCs can strongly influence community assemblages throughout alpine meadow retrogressive succession.

Keywords: Crust type; Seed position; Microenvironment; Germination; Tibetan Plateau; Vascular plants

\section{Introduction}

Biological soil crusts (BSCs), which can consist of cyanobacteria, algae, microfungi, lichen and/or moss (Belnap and Gillette 1998; Ferrenberg et al. 2015), live within or on the soil surface (Eldridge and Greene 1994), and are critical structural and functional components of many ecosystems (Bowker 2007; Zhang and Belnap 2015). They can have important impacts on ecological function through physiological or physical processes. For example, BSCs can bind soil particles to protect the surface soil from wind and water erosion (Belnap and Gardner 1993; Eldridge and Leys 2002; Veluci et al. 2006; Mazor et al. 1996); fix nitrogen (N) and carbon (C) to increase soil nutrients and $\mathrm{C}$ storage (Austin et al. 2004; Hawkes 2003; Evans and Ehleringer 1993; Lange et al. 1994); modify the balance between water run-off and infiltration (Kidron and Yair 1997; Eldridge and Greene 1994); and influence soil roughness. These changes can create a suitable primitive habitat for vascular plant growth, which influence on seed germination and establishment.

The influences of BSCs on seed germination and establishment has become an important research topic because, through these influences, BSCs can impact ecosystem succession ( $\mathrm{Li}$ et al.
2005; Hawkes 2004; Belnap et al. 2001). Studies have shown that BSCs can have facilitative (St Clair et al. 1984; Belnap and Harper 1995) and inhibitory (Hobs 1985; Eldridge et al. 2000) effects on seed germination. These contradictory findings may be due to differences in BSC composition ( $\mathrm{Su}$ et al. 2009), plant traits (special chemical and structural characteristics) (Zaady et al. 1997; Langhans et al. 2009; Belnap 2006; Deines et al. 2007), or even BSC succession stage (Zellman. 2002) between studies.

The experiments described above mainly investigated BSCs in arid and semi-arid ecosystems, especially in desert ecosystems ( $\mathrm{Li}$ et al. 2005; Rivera-Aguilar et al. 2005; Deines et al. 2007). Most of these studies were performed in relatively stable ecosystems, whereas BSCs proceed from early to late succession stages over long time periods. BSCs make up an important component of all alpine meadow ecosystems (Wang et al. 2014), but the BSC type and coverage changes with alpine meadow succession (Li et al. 2015). BSCs in alpine meadows are a special case, because they are the result of intensive land use, especially overgrazing, and alpine meadow is fine-textured. Extensive grazing pressure was shown to result in alpine meadow succession from Graminoid dominated zonal vegetation to Kobresia humilis meadow, and then to K. pygmaea meadow (Lin et al. 2015). These three meadow succession stages correspond with BSC succession from moss-dominated crust to cyanobacteria-dominated crust, and then lichendominated crust. Especially in K. pygmaea meadows, BSC, which mainly consist of cyanobacteria and lichen, grow aggressively, occupying large areas of the meadow. These cyanobacteria and lichen crusts, form a tight thin layer on the soil surface, and make profound changes to the soil microenvironment which is specific to the BSC components (Li et al.2015). An important question is how the changes to the alpine meadow microenvironment caused by the succession of BSCs affect germination of seeds banked in the soil and seeds dispersed to the soil surface. In alpine meadows, soil crack formations are very common, especially in the late succession stage, due to freezing and thawing and disturbance effects of rodents burrowing in the soil. These cracks result in meadow patchiness and landscape fragmentation ( $\mathrm{Li}$ et al. 2010). BSCs may 
contribute to the development of patchy vegetation patterns through effects on seed germination and establishment (Deines et al. 2007), which may play an important role in alpine meadow community succession. With alpine meadow retrogressive succession, the succession of BSCs follows plant community succession, but the roles of BSCs play in these succession stages are still not clearly understood. Therefore, we studied germination of three native vascular plant species (belonging to three functional groups) within four crust types, which represent the typical four degraded stages of alpine meadow BSC succession. We were interested in investigating whether seed position (surface vs sub-surface) or soil texture (cracks vs no-cracks) impacted seedling emergence within the different alpine meadow and BSC succession stages. Our goal was to determine whether different types of BSCs could act as natural barriers to germination in different vascular plant. Therefore, we aimed to test the following hypotheses:

(1) Seed position and crack formation have strong effects on germination success. Subsurface soil provides a more favorable environment for seed germination than the soil surface, and the effects of crack formation will vary with different BSC types.

(2) Cyanobacteria and lichen crusts will inhibit seed germination due to their barrier function (i.e. they form continuous layers over the soil).However, seed germination will increase with moss crusts because moss crusts provide more moisture retention.

\section{Methods}

\subsection{Study area and collection of typical habitat species' seeds:}

The study area was located in the town of Huangcheng at the northeast edge of the Qinghai-Tibetan Plateau $\left(37^{\circ} 39.876^{\prime} \mathrm{N}, 101^{\circ} 10.748^{\prime}\right.$ $\mathrm{E}, 3227 \mathrm{~m}$, above sea level, Figure 1), within a typical plateau continental climate. During the period from 1976 to 2001, the average annual air temperature was $-1.7^{\circ} \mathrm{C}$ and the average annual precipitation was $500 \mathrm{~mm}$, with $85 \%$ of the annual rainfall concentrated within the growing season from May to September. The soil type within the study area was alpine meadow soil.

The alpine meadows within the study area have been used as winter and spring pasture. Animals grazing cross the study area include yak and Tibetan sheep. Grazing intensity varied throughout the study area based on sheep stocking density. Meadows were stocked with four different densities of sheep: $3.65,7.50,8.25$, and 11.25 sheep unit ha-1 (Lin et al. 2016; Figure 1). Different grazing intensities created alpine meadows that had been retrogressively degraded into 4 typical succession stages (Cao et al. 2007). The graminoiddominated alpine meadow (zonal alpine meadow vegetation made up of two-layered communities with $90 \%$ vegetative cover, and grasses reaching up to $60 \mathrm{~cm}$ ), graminoid+sedge-dominated succession stage, was approximately $80 \%$ vegetative cover, with $K$. humilis as the dominant sedge species. The $K$. pygmaea meadow succession stage had overall vegetative cover of $60 \%$ to $70 \%$, and $K$. pygmaea was the dominant species, with an average height of $10 \mathrm{~cm}$. The cracked turf succession stage of $K$. pygmaea meadows was characterized with dense crack formation on the soil surface. The type and morphology of BSCs varied with the alpine

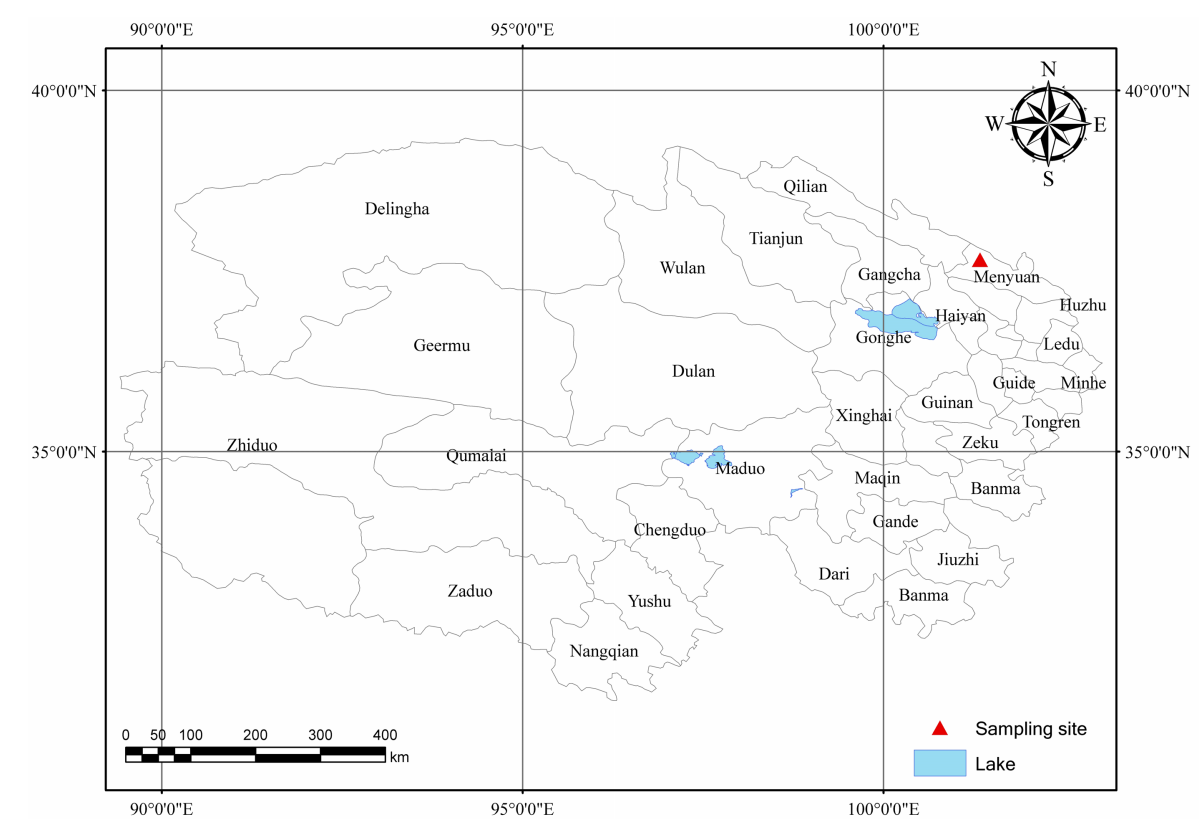

Figure 1 Location of experimental plot in Qinghai province of China. 
meadow plant community succession types.

\subsection{Investigated species}

In this study, we chose three perennial habittypical species, i.e. Poa pratensis L., Tibetia himalaica T. and Potentillen nivea L. Plant seeds were collected from at least 10 plants per species within the study site from August to September 2013 according to their maturing timing of each species. Mature seeds were stored dry in a freezer below $-20^{\circ} \mathrm{C}$ to simulate vernalization until spring 2014, when seeds were thawed, stored at $4^{\circ} \mathrm{C}$ for about 2 weeks until processing (May 2014).

\subsection{BSCs collection}

In the mid April, we carefully translocated soil monoliths, which measured $10 \mathrm{~cm} \times 10 \mathrm{~cm} \times 1-1.5$ cm (length $\times$ width $\times$ height) and represented the typical BSCs within the sample site, from the 4 different alpine meadow succession stages (Figure 2). The four representative BSC succession stage types were moss crust, moss + cyanobacteria crust, cyanobacteria crust, and lichen crust, which corresponded with the graminoid-dominated alpine meadow, the graminoid+sedge-dominated succession stage, the $K$. pygmaea meadow succession stage, and the cracked turf succession stage of $K$. pygmaea meadows, respectively. First the ground was wetted to facilitate removal of intact BSCs, then the BSC sample was moved using a soil knife and shovel, and the bottom of the BSC was smoothed using a knife. The BSC samples were watered daily in order to encourage germination of

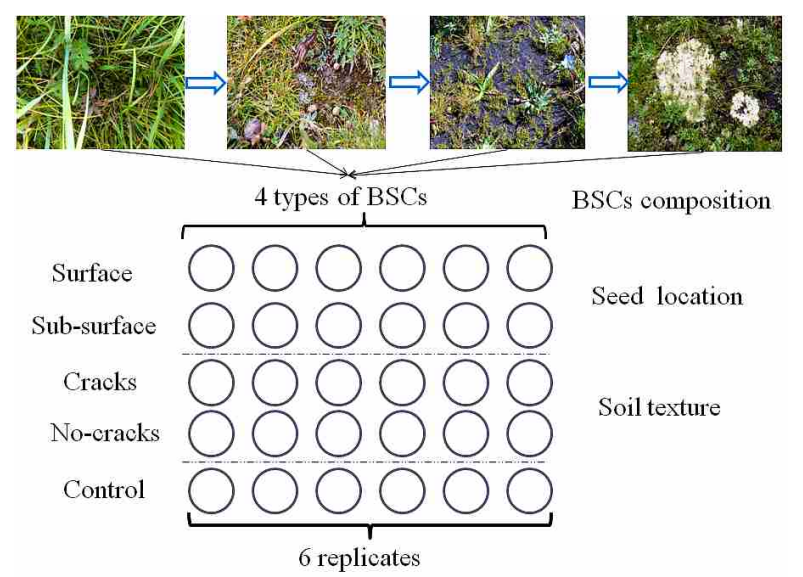

Figure 2 The four BSC succession stages and experiment design. all seeds within samples. Once no seedlings sprouted from the sample for seven consecutive days, the sample was considered to be seed-free and ready for germination experiments ( $\mathrm{Su}$ et al. 2007; Zhang and Belnap 2015).

\subsection{Experiment 1}

Experimental trays $(12.0 \mathrm{~cm} \times 12.0 \mathrm{~cm} \times 3.0$ $\mathrm{cm}$ ) (length $\times$ width $\times$ height) were prepared with BSCs or sterilized sand. Autoclaved sand $(3 \mathrm{~cm})$ was used as the sterile control and a layer of BSC $(1-1.5 \mathrm{~cm}, 10 \mathrm{~cm} \times 10 \mathrm{~cm})$ on the top of autoclaved sand $(2 \mathrm{~cm})$ was used as the experimental treatment for common garden experiments. Tray bottoms were lined with gauze to prevent seed loss. Each tray was planted with 25 seeds per species, which were either spread randomly on the surface of the crust (simulating natural seed dispersal) or inserted 1-1.5 cm deep into the crust or bare sand (mimicking emergence out of the seed bank). For each species and treatment, there were 6 replicates (Figure 2). Trays were placed outside to mimic field conditions, and all samples were kept moist with daily $300 \mathrm{ml}$ watering. The common garden experiment started in May.

Within the moss crust samples at the beginning of the common garden experiment, mean moss cover was $79.3 \% \pm 2.6 \%($ mean $\pm \mathrm{SE}$ ), and moss normally grow to a height of $0.5-1.5 \mathrm{~cm}$; For moss + cyanobacteria crust samples, the mean cover of moss and cyanobacteria, respectively was $46.7 \% \pm 3.8 \%$ and $43.8 \% \pm 2.2 \%$. The moss height $(0.5 \mathrm{~cm})$ was lower than in the moss crusts samples.; In cyanobacteria crusts samples, the mean cyanobacteria cover was $81.0 \% \pm 1.0 \%$; that is the cyanobacteria covered nearly the entire space between vascular plants; In the lichen crust samples, the mean cover with lichen crust was of $55.8 \% \pm 2.4 \%$, and the main species of lichen were Diploschistes diacapsis, Endocarpon spp. and Cladonia spp.

\subsection{Experiment 2}

In the cracked turf succession stage of $K$. pygmaea meadows, the turf is often cracked from freezing and thawing or other disturbance (e.g., pika burrowing behavior or yak trampling). These cracks influence the BSCs of alpine meadows. In 
order to investigate seed emergence from this microhabitat, the same experimental procedure as for Experiment 1 was followed. The pots were concurrently placed in the same place as the Experiment 1 trays. Radical emergence from seeds was recorded daily and used to calculate percent germination (Zhang and Belnap 2015)

Experiment 1 and 2 were also devised to distinguish between effects of four crust types on seedling emergence due to (1) physical structure or (2) crust type. There were 120 trays we set in the experiment.

\subsection{Germination experiment}

Seeds were randomly placed on the soil surface or buried into the soil to mimic initial position of seeds after wind dispersal and germinated from the soil seed bank, respectively. For the cracked crust test, seeds were also randomly placed on the soil surface. Germination was recorded as radical emergence (approximately $2 \mathrm{~mm}$ ) daily (Deines et al. 2007), and trials were terminated after no seed germinated occurred for seven consecutive days (Grime et al. 1981). Trials lasted for 26 days. At the end of trials, the seedlings were removed from the soil samples to examine root growth and confirm that the radical emerged from seeds, and not by propagation.

We also investigated the occurrence frequency of three plant species within alpine meadows to test for correlations between occurrence frequency and germination rate. Occurrence of the three plant species was estimated in August 2013 within six $0.25 \mathrm{~m}^{2}$ quadrats selected randomly within the different grazing intensity areas. Soil water content is an important factor that influences seed germination, and BSCs may influence moisture status of seeds embedded in the crust (Belnap et al. 2001). Additionally, trampling by grazers can reduce moisture infiltration rates, surface sealing, and crust formation (Cerdà and Lavée 1999; Cao et al. 2007). Therefore, we measured soil water content for every succession stage and compared soil water content between cyanobacteria crust patches and adjacent plant patches. We used a Time-Domain Reflector (TDR) to measure soil water content at $0-10 \mathrm{~cm}$ depth and each plot was sampled 12 times. Significance was set at a level of $p<0.05$.

\subsection{Statistical analyses}

Emergence data was analyzed using a Mixed Linear Model with seedling emergence as the response variable and species, seed position (surface vs subsurface), and soil texture (cracks vs no-cracks) as the dependent variables (SPSS 16, IBM, Chicago, USA). All differences were tested for at a significance level of $p<0.05$. Effects of seed position and soil texture on germination in the three species were compared using independent samples $\mathrm{T}$ tests. Effects of crust types on seed germination were tested using a one-way ANOVA, followed by the least significant difference (LSD) post hoc test when significant differences between means were observed. Correlations between germination rates within typical alpine meadow BSCs and species occurrence within the alpine meadow were tested for the three vascular plant species using bivariate correlations.

\section{Results}

\subsection{Influence of BSCs on seed germination}

Germination varied significantly with species $(p<0.001) ;$ BSCs strongly influenced species germination on the whole (Table 1; for Experiment

Table 1 Results of the mixed linear models predicting effects of species, BSC type, seed position, and soil texture on seedling emergence

\begin{tabular}{|l|l|l|l|l|l|}
\hline Experimental 1 & $F$ & $P$ & Experimental 2 & $F$ & $P$ \\
\hline Species & 154.368 & $<0.000$ & Species & 606.944 & $<0.000$ \\
\hline Type & 2.766 & 0.045 & Type & 6.851 & $<0.000$ \\
\hline Position & 92.403 & $<0.000$ & Texture & 37.499 & $<0.000$ \\
\hline Species $\times$ Type & 1.458 & 0.198 & Species $\times$ Type & 1.616 & 0.149 \\
\hline Type $\times$ Position & 11.465 & $<0.000$ & Type $\times$ Texture & 2.286 & 0.082 \\
\hline Species $\times$ Position & 3.064 & 0.031 & Species $\times$ Texture & 7.967 & 0.001 \\
\hline Species $\times$ Type $\times$ Position & 0.266 & 0.952 & Species $\times$ Type $\times$ Texture & 5.472 & $<0.000$ \\
\hline
\end{tabular}

Notes: Species $=$ the three species studied in this experiment; Type $=$ four types of BSC; Position = surface or subsurface; Texture $=$ cracked or crack free. 
1, $p=0.045$; for Experiment 2, $p<0.001$ ) in both experiments. Crust type did not significantly influence emergence for any of the three species in experiment 1 (Table 2, $p>0.05$ ), but significantly affected emergence for all three species in experiment 2 (Table 2, $p<0.05$ ). For $P$. pratensis, the germination rates in moss $(40.0 \%)$ and cyanobacteria $(46.1 \%)$ crusts were lower than in other crust types; however, the subsurface germination rates were nearly the same for all crust types (Table 3); BSC succession type had no significant effect on $T$. himalaica germination rates, which were very low within all crust types and locations. Cyanobacteria crusts significantly restrained surface $P$. nivea seed germination compared to germination on moss crusts $(p<0.05)$, but had no influence on subsurface germination (Table 3)

Experiment 2 showed crust type significantly influence germination rates of all three species (Table 2, $p<0.01$ ). Effects of crust surface texture on seed germination depended on BSC type (Table $4)$, however, crack-free cyanobacteria crust ( $p<$ o.01) and, especially, crack-free lichen crust $(p<$ o.01) drastically decreased germination rates of $P$. pratensis (Table 4). Crack formation significantly increased the germination rate of $P$. pratensis in three crust succession types, whereas it significantly affected $T$. himalaica only on the cyanobacteria crust $(p<0.01)$. On Cracked crusts, crust succession type had no significant effect on $T$. himalaica germination rate $(p>0.01)$. On crackfree crusts, however, cyanobacteria crust formation significantly suppressed $T$. himalaica germination, relative to germination of the same species on the other three crust succession types and controls.

\subsection{Influence of the microenvironment on seed germination}

The microenvironment influenced seed germination. Seed position significantly influenced germination rates (Table $1, p<0.001$ ) for all three studied plant species (Table 2, $p<0.000$ for $P$. pratensis and T. himalaica, and $p<0.030$ for $P$. nivea). The interactions between crust type and seed position and between species and seed position were significant (Table $1, p<0.05$ ). For all

Table 2 Results of the mixed linear models predicting effects of seed position and soil texture (cracked and crackfree) on seedling emergence

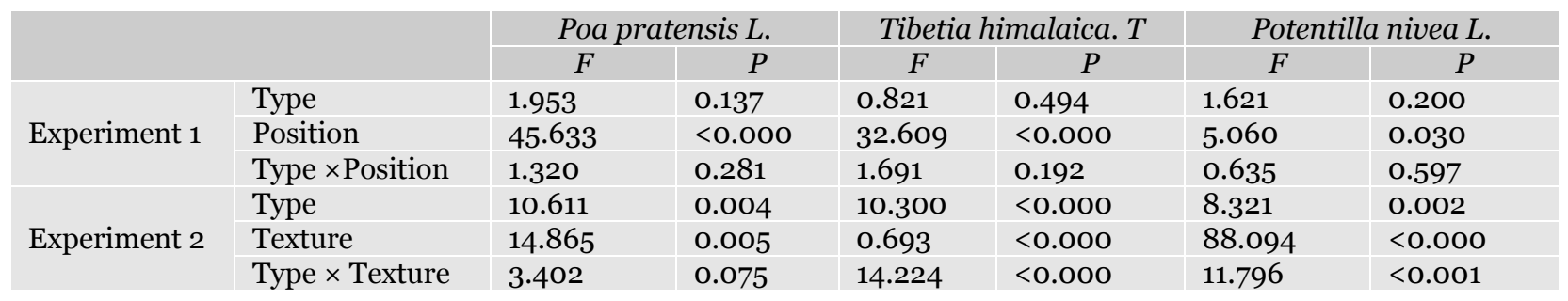

Table 3 Influence of seed position on vascular seed germination rate

\begin{tabular}{l|l|l|l|l|l|l|} 
Species & Position & Moss & Moss+cyanobacteria & Cyanobacteria & Lichen & Control \\
Poa pratensis $L$. & Surface & $40.0 \pm 10.2 \mathrm{~b}^{*} \mathrm{~B}$ & $68.3 \pm 10.0 \mathrm{~b}^{*} \mathrm{AB}$ & $46.1 \pm 13.3 \mathrm{~b}^{*} \mathrm{~B}^{*}$ & $70.6 \pm 13.9 \mathrm{~b}^{*} \mathrm{AB}$ & $93.9 \pm 4.3 \mathrm{aA}$ \\
& Subsurface & $100.0 \pm \mathrm{OAAB}$ & $100.0 \pm \mathrm{OaAB}$ & $92.8 \pm 6.6 \mathrm{aB}$ & $100.0 \pm \mathrm{OAB}$ & $100+0.0 \mathrm{~A} A$ \\
Tibetia & Surface & $2.7 \pm 0.8 \mathrm{aAB}$ & $2.7 \pm 1.9 \mathrm{bAB}$ & $1.3 \pm 0.8 \mathrm{~b} \mathrm{~b}^{*} \mathrm{~B}$ & $2.7 \pm 2.0 \mathrm{bAB}$ & $6.7 \pm 1.7 \mathrm{aA}$ \\
himalaica.T & Subsurface & $4.7 \pm 1.2 \mathrm{aA}$ & $8.7 \pm 1.9 \mathrm{aA}$ & $8.0 \pm 3.1 \mathrm{aA}$ & $9.3 \pm 1.3 \mathrm{aA}$ & $9.7 \pm 4.0 \mathrm{~A}$ \\
\hline $\begin{array}{l}\text { Potentillen nivea } \\
\text { L. }\end{array}$ & Surface & $18.0 \pm 5.7 \mathrm{aA}$ & $14.0 \pm 4.6 \mathrm{aAB}$ & $5.3 \pm 1.3 \mathrm{bB}$ & $12.7 \pm 4.3 \mathrm{aAB}$ & $8 \pm 3.6 \mathrm{aAB}$ \\
\hline & Subsurface & $30.7 \pm 12.1 \mathrm{aA}$ & $20.7 \pm 4.6 \mathrm{aAB}$ & $21.3 \pm 3.2 \mathrm{aAB}$ & $14.0 \pm 3.8 \mathrm{aAB}$ & $4.7 \pm 1.6 \mathrm{aB}$
\end{tabular}

Notes: Different capital letters within the same row indicate significant differences at $p<0.05$; different lowercase letters within the same column indicate significant differences between surface textures for the same species at $p<$ 0.05. * indicates significance at $p<0.01$. The same statistical symbol protocol was applied to Table 4 .

Table 4 Influence of soil texture on vascular seed germination rate

\begin{tabular}{|c|c|c|c|c|c|c|}
\hline Species & Texture & Moss & Moss+cyanobacteria & Cyanobacteria & Lichen & Control \\
\hline \multirow{2}{*}{ Poa pratensis $L$. } & Cracks & $100 \pm 0 a \mathrm{~A}$ & $94.5 \pm 3.6 \mathrm{aA}$ & $100.0 \pm 0 a A$ & $92.8 \pm 5.0 a A$ & $100 \pm 0.0 a A$ \\
\hline & cks & $91.7 \pm 4$. & 93.3 & $76.1 \pm 15 \cdot 3 \mathrm{~b}^{*} \mathrm{BC}$ & $59 \cdot 5^{ \pm 9} \cdot 3 \mathrm{~b}^{*} \mathrm{C}^{*}$ & $00 \pm 0.0 a A$ \\
\hline \multirow{2}{*}{ Tibetia himalaica.T } & $\mathrm{Cr}$ & $4.0 \pm 1$ & $7 \cdot 3 \pm 1$ & 4.7 & $6.0 \pm 1$. & $9.3 \pm 1.7 \mathrm{aA}$ \\
\hline & No- & $6.0 \pm 2.7 \mathrm{aAB}$ & $10.0 \pm 3.2 \mathrm{aA}$ & $\mathrm{O} \pm \mathrm{Ob}^{*} \mathrm{C}^{*}$ & $3 \cdot 3 \pm 1$ & $8.7 \pm 1.6 \mathrm{aA}$ \\
\hline \multirow{2}{*}{ Potentillen nivea $L$. } & $\mathrm{Crac}$ & $25 \cdot 3 \pm 3.2 \mathrm{a} \mathrm{B}{ }^{*} \mathrm{C}$ & 47. & 33 . & $18.7 \pm 2.2 \mathrm{aBC}$ & $14.7 \pm 6.1 \mathrm{aC}$ \\
\hline & No-cracks & $20.7 \pm 3.5 \mathrm{aA}$ & $\mathrm{O} \pm \mathrm{ObB}$ & $14.7 \pm 5.4 \mathrm{bA}$ & $3.3 \pm 1.2 b^{*}$ & $16 \pm 3.7 \mathrm{aA}$ \\
\hline
\end{tabular}


BSC types, seed germination rate of $P$. pratensis in subsurface soil was significantly higher than on the surface soil, however, for the same seed position, germination rates of $P$. pratensis did not differ among crust succession types (Table 3). Seed germination rates on surface and subsurface did not differ for T. himalaica between moss crust and control treatments (Table $3, p>0.05$ ). However, within the three later BSCs succession stages, germination rates of $T$. himalaica significantly differed between surface and subsurface (Table $3, p$ $<$ 0.05). For $P$. nivea, germination rates on both surface and subsurface only differed in cyanobacteria succession stage crust. These results indicate that seed location and BSC succession stage have different influences on seed germination rates for the three plant species studied.

Seed germination was significantly influenced by soil texture (Table 1 and 2), the interactions between species and texture, and the interaction among species, crust succession type, and texture. The interactions between crust type and texture had a significant effect on seed germination rates of $T$. himalaica and $P$. nivea (Table $2, p<0.01$ ). This suggests that soil texture strongly influences seed germination in a species-specific manner in alpine meadows.

Germination rates of $P$. pratensis on crackfree cyanobacteria crust and crack-free lichen crust were significant decreased ( $p<0.01$, No-cracks condition) compared with crack formation (Table 4). These results show that crack formation significantly increased seed germination rates for $P$. pratensis on three different crust types.

The germination rates of $T$. himalaica were very low (Table 4). Crack formation significantly influenced germination rates of this species only on the cyanobacteria crust $(p<0.01)$. Cracks-free cyanobacteria crust and Crack-free lichen crust significantly suppressed $T$ himalaica germination relative to germination on cracked crust.

\subsection{Correlations between seed germination and plant occurrence frequency}

Historically, extensive and selective grazing have been regarded as the main factors causing degradation in alpine meadow, with alpine meadow retrogressive succession, growth and distribution of different plant functional groups changing according to their responses to grazing pressure and their reproductive strategies. Our experiments showed strong relationships between surface seed germination rates and species occurrence frequency within the alpine meadow only for $T$. himalaica. For the other two study species, there was no significant correlation between surface seed germination rate and their occurrence within the alpine meadow (Table 5). This poor correlation between occurrence and seed germination for the two perennial species may be explained by the importance of propagation through rhizomes for these two species.

Table 5 Correlation between plant seed emergence rate and plant occurrence frequency in an alpine meadow

\begin{tabular}{|l|l|l|l|} 
& $\begin{array}{l}\text { Poa } \\
\text { pratensis L. }\end{array}$ & $\begin{array}{l}\text { Tibetia } \\
\text { himalaica. T }\end{array}$ & $\begin{array}{l}\text { Potentilla } \\
\text { nivea L. }\end{array}$ \\
\hline $\begin{array}{l}\text { Surface } \\
\text { Sub- } \\
\text { surface }\end{array}$ & 0.841 & 0.000 & 0.383 \\
\hline
\end{tabular}

\section{Discussion}

The traditional BSCs succession course in arid or semi-arid ecosystems proceeds from the early cyanobacteria crust successional stage into latersuccessional communities of lichen and moss crusts (Belnap and Elgredge 2003); however, in alpine meadows, BSC succession differs. BSC succession in arid and semiarid ecosystems occurs through natural processes and over long time periods. In contrast, BSC succession in alpine meadows is driven by plant community succession, which is highly influenced by extensive animal grazing, and proceeds relatively quickly.

\subsection{The barrier effects of BSCs on seed germination}

Our study showed that each of the four different types of BSCs had significant effects on the germination of three perennial grass species common to different alpine meadow succession stages; this is consistent with former studies (Zaady et al. 1997; Langhans et al. 2009). Crust type significantly influenced seed germination rates (Table 1) for all three plant species studied. Cyanobacteria crust significantly lowered surface seed germination rates relative to controls and all 
other BSC types. This finding of cyanobacteria crust acting as a barrier to seed germination differs from findings of previous studies (Zaady et al. 1997). Cyanobacteria crust may impair seed germination through decreasing soil water content (Figure 3 and Figure 4). Under wet conditions a thick cyanobacteria crust develops, which limit rain water infiltration and, therefore, limit water availability for the perennial vegetation (Ram and Aaron 2007; Li et al. 2006). In contrast, the other crust types had variable influences on germination rates of subsurface seeds from the three plant species studied (Table 3). Intact BSCs can suppress germination of weedy forbs and enhance germination in native perennial grass (Eldridge and Simpson 2002). BSCs can also differently affect germination in native species (Hawkes 2004).The effects of BSCs on seed germination observed in these studies suggest that BSC

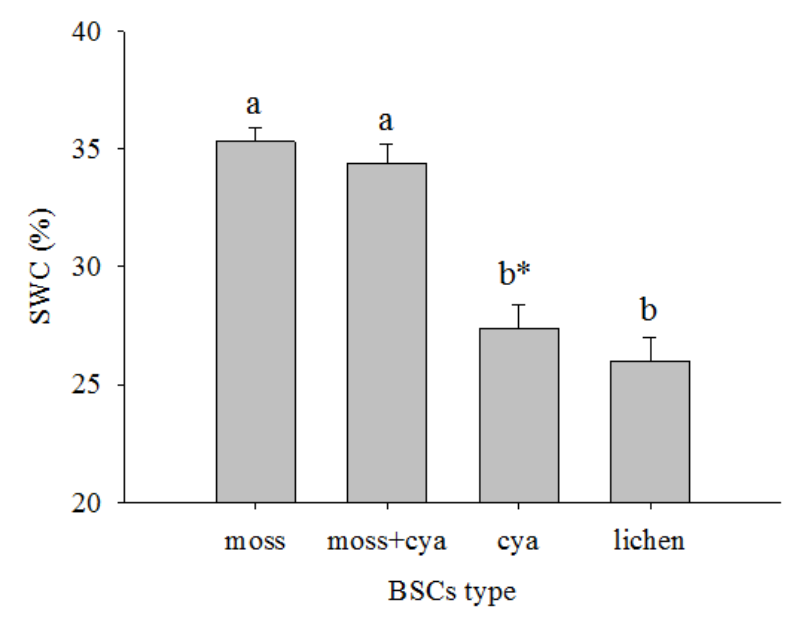

Figure 3 Soil water content changes with BSC succession (cya indicate cyanobacteria).

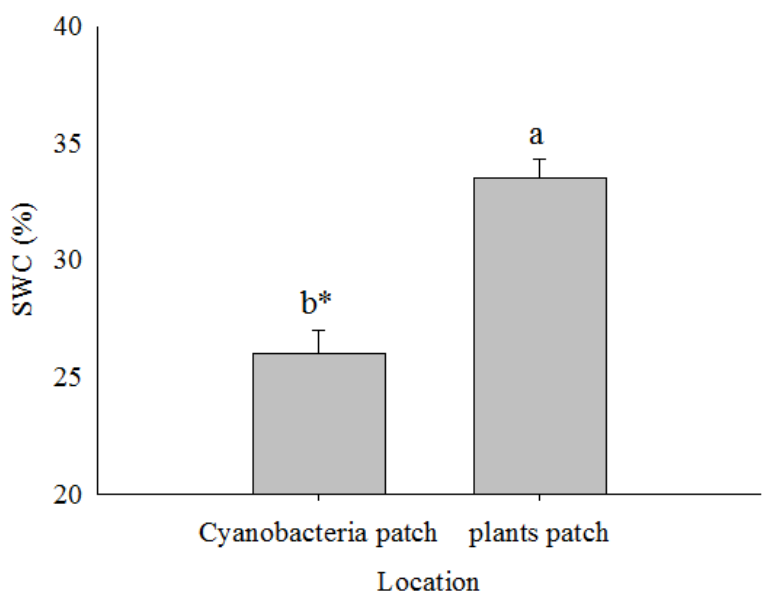

Figure 4 Soil water content of cyanobacteria patches and plant patches. formation and succession can strongly influence the distribution of plant species, and eventually affect alpine meadow plant succession.

Seed position is important for seed germination. Influences of seed location differed among the three plant species tested. Germination rates of $P$. pratensis and $T$. himalaica seeds were significantly affected by location, but for $P$. nivea, seed location only affected germination rates within cyanobacteria crust succession type treatments. These results show cyanobacteria crust to be less favorable for perennial vascular plant seed germination than other crust types, which is consistent with the findings of Zaady et al. (1997) that reported cyanobacteria crusts to inhibit germination of the annual plants Plantago and Reboudia in Israel. The results of this study show that crust type, seed position, and their interaction strongly influence seed germination.

$\mathrm{Li}$ et al. (2005) found that seedling emergence was more successful in moss crusts than in algal crusts, but the present study demonstrated exceptions to these trends. Germination of some plant species was improved in moss crust, while other species had better germination rate in cyanobacteria crust. This variation may be related to moss height, because if the moss grows high, surface seeds will not make contact with the soil, and moisture levels will be insufficient for germination. However in another study, Serpe et al. (2006) observed that a biological soil crust dominated by short moss significantly inhibited germination of cheatgrass and three perennial grasses, while tall moss crust had little effect on germination, which is not in accordance with our results.

Previous studies on effects of BSCs on vascular plant germination have found varying results. Studies on a range of different crust types have found negligible effects of BSCs on seedling germination (Beyschlag et al. 2007; Eldridge et al. 2000; Keizer et al. 1985; Sedia and Ehrenfeld 2003; Li et al. 2005; Sylla 1987), while other studies have reported positive effects of crusts on seed germination (Belnap 2002; Kleiner and Harper 1977; Boeken et al. 2004;). Previous studies have primarily focused on testing how changes to BSC over time influence seed germination (Langhans et al. 2009; Su et al. 2007 ), and previous field studies investigating natural dispersal and emergence have 
generally studied annual, not perennial plant species (Belnap and Harper 2001). However, in the harsh alpine meadow environment, perennial plants make up the most important component of the plant community. St. Clair et al. (1984) found that large increases in germination rates in two perennial grass species on crusted, relative to crust-free soils in the laboratory. Crisp (1975) in Australia found that establishment of the native perennial grass Stipa was not inhibited by crusts, whereas crusts did inhibit the annual grass Schismus. This study expanded on these previous findings to show that the positive or negative effects of BSCs on germination of alpine meadow perennial species can be influenced by the location of the seed within the soil.

Soil textures can influence seed germination. Previous studies have shown cracks in the soil surface to have positive effects on seed germination (Langhans et al. 2009). We found that crack formation tended to increase seed germination rates, especially in cyanobacteria and lichen crusts (Table 4). That is to say, cyanobacteria and lichen crusts without cracks decreased seed germination, and cracks in the same crust type improved seed germination. With alpine meadow degradation, the space separating plants increases; cyanobacteria and lichen form a thin layer on the soil surface, which unlike in arid and semi-arid ecosystems, is tightly bound with the soil, and is not easily be destroyed. That is, alpine meadow cyanobacteria and lichen crusts form a mechanical barrier over the soil surface. Our results showed crack-free cyanobacteria and lichen crusts inhibit $P$. pratensis seed germination. This inhibition may accelerate alpine meadow degradation. Indeed, the cyanobacteria crust succession stage is the ecosystem turning point from a degraded to a seriously and irreversible degraded alpine meadow. In the field we could observe more seedlings appeared in the cracked cyanobacteria and lichen crusts than in the place cyanobacteria and lichen crust occupied. When suitable micro-relief structures are not present on intact soil crusts to provide mechanical stability and sufficient moisture, seed germination is negatively impacted (Zaady et al. 1997; West 1990). Furthermore, interactions between BSC type and crust surface texture significantly influenced the three perennial vascular plant species examined in this study
(Table 1).This points towards an important role of BSCs in alpine meadow plant community succession, and loss or addition of BSCs may trigger transitions between steady ecosystem states. Our results also demonstrate that with alpine meadow degradation and BSC succession, BSCs impair seed germination of gramineous forage and other species, eventually resulting in the thorough degradation of the alpine meadow.

\subsection{Impacts of soil moisture variation with BSC types on seed germination}

BSCs affect the redistribution of runoff across the landscape and into soil (Eldridge et al. 2002). Our results show that soil water content to decrease with crust type succession, especially in meadows covered with cyanobacteria crust and lichen crust. A study performed in the Negev desert in Israel also found that removal of the thin cyanobacterial-dominant crust from a sandy dune and a well-developed lichen-dominant crust from a loess-covered hill slope resulted in a three to fivefold increased in sorptivity and steady-state infiltration under both ponding and tension (Eldridge et al. 2000), Deines et al (2007) regarded increases in seedling mortality on lichen crusts to be due to desiccation and inadequate water absorption. Spatial heterogeneity in landscapes is partly attributed to the presence of biological soil crusts; for example cyanobacteria crust patches can have lower water content than plant patches (Belnap et al. 2001). Through these influences on surface properties and water movement, BSCs play important roles in seedling emergence and establishment (Harper and Marble 1988; Zaady et al 1997) and eventually accelerate grassland retrogressive succession.

Alpine meadow retrogressive succession caused by extensive grazing is a growing concern. Succession of alpine meadow BSCs, which can influence seed germination, follow plant community succession (Bowker 2007). Therefore, it is crucial that ecosystem managers take measures to recover degraded alpine meadows with regard of BSCs conditions. One such effective measure is reseeding to recover specific degraded succession stages; therefore knowledge of the influences of BSCs on seed germination is crucial for effective restoration of degraded meadows. 


\section{Conclusions}

BSC succession type significantly influenced seed germination rate, and this influence varied with BSC types. Effects of BSC on seed germination were influenced by seed position and soil surface structure. In some cases, BSCs became a barrier to plant seed germination. These results indicate that BSCs can serve as a biological filter during seed germination. Therefore, BSC succession may be an important trigger determining plant species diversity and community structure in alpine meadows. Future studies should make a full assessment of overall survival rates of vascular plant species and the influences of different BSC types on annual plant seed germination.

\section{References}

Austin AT, Yahdjian L, Stark JM, et al.(2004) Water pulses and biogeochemical cycles in arid and semiarid ecosystems. Oecologia141(2): 221-235. DOI: 10.1007/so0442-004-1519-1

Belnap J (2002) Nitrogen fixation in biological soil crusts from southeast Utah, USA. Biology and Fertility of Soils 35: 128135. DOI: 10.1007/s00374-002-0452-x

Belnap J (2006) The potential roles of biological soil crusts in dryland hydrologic cycles. Hydrological Processes 20: 31593178. DOI: 10.1002/hyp.6325

Belnap J, Eldridge D (2003) "Disturbance and recovery of Biological Soil Crusts." Biological soil crusts: structure, function, and management. Springer Berlin, Heidelberg. pp 363-383.

Belnap J, Gardner JS (1993) Soil microstructure in soils of the Colorado Plateau: the role of the cyanobacterium Microcoleus vaginatus. Great Basin Naturalist 53(1):40-47.

Belnap J, Gillette DA (1998) Vulnerability of desert biological soil crusts to wind erosion: the influences of crust development, soil texture, and disturbance. Journal of Arid Environments 39(2): 133-142. DOI:10.1006/JARE.1998.0388

Belnap J, Harper KT (1995) Influence of cryptobiotic soil crusts on elemental content of tissue of two desert seed plants. Arid Soil Research and Rehabilitation 9:107-115. DOI 10.1080/ 15324989509385879

Belnap J, Prasse R, Harper KT (2001) Influence of biological soil crusts on soil environments and vascular plants. Springer-Verlag Berlin Heidelberg Ecological Studies 150: 281-300. DOI: $10.1007 / 978-3-642-56475-8 \_21$

Beyschlag W, Wittland M, Jentsch A, et al. (2008) Soil crusts and disturbance benefit plant germination, establishment and growth on nutrient dificient sand. Basic and Applied Ecology 9(3): 243-252. DOI: 10.1016/j.baae.2007.03.002

Bowker MA (2007) Biological soil crust rehabilitation in theory and practice: an underexploited opportunity. Restoration Ecology 15(1):13-23. DOI: 10.1111/j.1526-100X.2006.00185.x

Boeken B, Ariza C, Gutterman Y, et al. (2004) Environmental factors affecting dispersal, germination and distribution of Stipa capensis in the Negev Desert, Israel. Ecological Research. 19:533-540.DOI:10.1111/j.1440-1703.2004.00666.x Cao GM, Du YG, Wang QL, et al. (2007) Character of passiveactive degradation process and its mechanism in Alpine

\section{Acknowledgements}

This study was funded by the Chinese National Natural Scientific Foundation (Grant No. 31270576) and by the grant (Grant No. 2016-ZJ-710) from Qinghai Province and Key laboratory of crop molecular breeding of Qinghai Province. We appreciate it greatly to the help of Professor J. H. C. Cornelissen for his valuable suggestion on this manuscript. We also extend our thanks to the journal's editors and two anonymous reviewers for their comments on earlier versions of this manuscript.

Kobresia meadow. Journal of Mountain Science 25(6): 641648. (In Chinese). DOI: 10.16089/j.cnki.1008-2786.2007. 06.016

Cerdà A, Lavée H (1999) The effect of grazing on soil and water losses under arid and Mediterranean climates. Implications for desertification, Pirineos. 153-154: 159-174. DOI: 10.3989/ pirineos.1999.v153-154.111

Crisp MD (1975) Long-term change in arid zone vegetation. $\mathrm{PhD}$ thesis, University of Adelaide, Adelaide, Australia.

Deines L, Rosentreter R, Eldridge DJ, et al. (2007) Germination and seedling establishment of two annual grasses on lichendominated biological soil crusts. Plant and Soil 295: 23-35. DOI:10.1007/s11104-007-9256-y

Eldridge DJ, Greene RSB (1994) Microbiotic soil crusts: a review of their roles in soil and ecological processes in the rangelands of Australia. Australian Journal of soil Research 32: 389-415. DOI: 10.1071/SR9940389

Eldridge DJ, Leys JF (2002) Exploring some relationships between biological soil crusts, soil aggregation and wind erosion. Journal of Arid Environments 53: 457-466. DOI: 10.1006/jare.2002.1068

Eldridge DJ, Simpson R (2002) Rabbit (Oryctolagus cuniculus L.) impacts on vegetation and soils, and implications for management of wooded rangelands. Basic and Applied Ecology 3: 19-29. DOI: 10.1078/1439-1791-O0078

Eldrideg DJ, Zaady E, Shachak M (2000) Infiltration through three contrasting biological soil crusts in patterned landscapes in the Negev, Israel. Catena 40: 323-336. DOI: 10.1016/So341-8162(00)0oo82-5

Eldridge DJ, Semple WS, Koen TB (2000) Dynamics of cryptogamic soil crusts in a derived grassland in southeastern Australia. Australia Ecology 25: 232-240. DOI: 10.1046/j. 1442-9993.2000.01023.x

Evans RD, Ehleringer JR (1993) A break in the nitrogen cycle of aridlands? Evidence from $\delta 15 \mathrm{~N}$ of soils. Oecologia 94(3): 314317. DOI: $10.1007 /$ BFo0317104

Ferrenberg S, Reed SC, Belnap J (2015) Climate change and physical disturbance cause similar community shifts in biological soil crusts. PNAS 112 (39): 12116-12121. DOI: 10.1073/pnas.1509150112

Grime JP, Mason G, Curtis AV, et al. (1981) A comparative study 
of germination characteristics in a local flora. Journal of Ecology 69: 1017-1059. DOI: 10.2307/2259651

Harper KT, Marble JR (1988) A role for nonvascular plants in management of arid and semiarid rangelands. Handbook of vegetation science 14: 135-169. DOI: 10.1007/978-94-0093085-8_7

Hawkes CV (2003) Nitrogen cycling mediated by Biological Soil Crusts and arbuscular mycorrhizal fungi. Ecology 84(6): 1553-1562. DOI: 10.1890/0012-9658(2003)084[1553:NCMB BS]2.0.CO;2

Hawkes CV (2004) Effects of biological soil crusts on seed germination of four endangered herbs in a xeric Floride shrubland during drought. Plant Ecology 170: 121-134. DOI: 10.1023/B:VEGE.0000019035.56245.91

Hobs RJ (1985) The persistence of Cladonia patches in closed heathland stands. Lichenologist 17: 103-109 DOI: 10.1017/ So024282985000111

Keizer PJ, van Tooren BF, During HJ (1985) Effects of bryophytes on seedling emergence and establishment of short -lived forbs in chalk grassland. The Journal of Ecology 73: 493-504. DOI: 10.2307/2260489

Kidron GJ, Yair A (1997) Rainfall-runoff relationships over encrusted dune surfaces, Nizzana, western Negev, Israel. Earth Surface Processes Landforms 22(12): 1169-1184. DOI: 10.1002/(SICI)1096-9837(199712)22:12<1169::AID-ESP812> 3.o.CO;2-C

Kleiner EF, Harper KT (1977) Occurrence of four major perennial grasses in relation to edaphic factors in a pristine community. Journal of Range Management 30:286-289. DOI: $10.2307 / 3897307$

Lange OL, Meyer A, Zellner H, et al. (1994) Photosynthesis and water relationships of lichen soil crusts: field measurements in the coastal fog zone of the Namib desert. Functional Ecology 8: 253-264. DOI: 10.2307/2389909

Langhans TM, Storm C, Schwabe A (2009)Biological soil crusts and their microenvironment: Impact on emergence, survival and establishment of seedlings. Flora - Morphology, Distribution, Functional Ecology of Plants 204(2): 157-168. DOI: 10.1016/j.flora.2008.01.001

Li XR, Jia XH, Long LQ, et al. (2005) Effects of biological soil crusts on seed bank, germination and establishment of two annual plant species in the Tengger Desert (N China). Plant and Soil 277(1): 375-385. DOI: 10.1007/s11104-005-8162-4

Li XR, Xiao HL, He MZ, et al. (2006) Sand barriers of straw checkerboards for habitat restoration in extremely arid desert regions. Ecological Engineering 28: 149-157. DOI: 10.1016/ j.ecoleng.2006.05.020

Li YK, Lin L, Zhang FW, et al. (2010) The main forage succession and ground surface characteristic changes during degradation and restoration of alpine Kobresia meadow. Acta Prataculturae Sinica 19(5): 179-185

Li YK, Ouyang JZ, Lin L, et al. (2015) Evolution characteristics of biological soil crusts (BSCs) during alpine meadow degradation. Chinese Journal of Ecology 34(8): 2238-2244. (In Chinese). DOI: 10.13292/j.1000-4890.2015.0189

Lin L, Li YK, Xu XL, et al. (2015) Predicting parameters of degradation succession processes of Tibetan Kobresia grasslands. Solid Earth 6: 1237-1246. DOI: 10.5194/se-61237-2015

Lin L, Zhang DG, Cao GM, et al. (2016) Responses of soil nutrient traits to grazing intensities in alpine Kobresia meadows. Acta Ecologica Sinica 36(15): 1-8. (In Chinese).
DOI: $10.5846 /$ stxb201501090073

Mazor G, Kidron GJ, Vonshak A, et al. (1996) The role of cyanobacterial exopolysaccharides in structuring desert microbial crusts. FEMS Microbiology Ecology 21(2): 121-130. DOI: 10.1111/j.1574-6941.1996.tboo339.x

Ram A, Aaron Y (2007) Negative and positive effects of topsoil biological crusts on water availability along a rainfall gradient in a sandy arid area. Catena 70: 437-442. DOI: 10.1016/ j.catena.2006.11.012

Rivera-Aguilar V, Godinez-Alvarez H, Manuell-Cacheux I, et al. (2005) Physical effects of biological soil crusts on seed germination of two desert plants under laboratory conditions. Journal of Arid Environments 63(1): 344-352. DOI: 10.1016/ j.jaridenv.2005.03.012

Sedia EG, Ehrenfeld JG (2003) Lichens and mosses promote alternate stable plant communities in the New Jersey Pinelands. Oikos 100: 447-458. DOI: 10.1034/j.1600-0706. 2003.12058.x

Serpe MD, Orm JM, Barkes T, et al. (2006) Germination and seed water status of four grasses on moss-dominated biological soil crusts from arid lands. Plant Ecology 185: 163178. DOI: $10.1007 / \mathrm{S} 11258-005-9092-1$

St Clair LL, Webb BL, Johansen JR, et al. (1984) Cryptogamic soil crusts: enhancement of seedling establishment in disturbed and undisturbed areas. Reclamation and Revegetation Research 3(2): 129-136.

Su YG, Li XR, Cheng YW, et al. (2007) Effects of biological soil crusts on emergence of desert vascular plants in North China. Plant Ecology 191: 11-19. DOI: 10.1007/s11258-006-9210-8

Su YG, Li XR, Zheng JG, et al. (2009) The effect of biological soil crusts of different successional stages and conditions on the germination of seeds of three desert plants. Journal of Arid Environments 73: 931-936. DOI: 10.1016/j.jaridenv. 2009.04.010

Sylla D (1987) Effect of microphytic crust on emergence of range grasses. MSc Thesis, School of renewable natural resources. The University of Arizona, AZ, USA

Veluci RM, Neher DA, Weicht TR (2006) Nitrogen fixation and leaching of biological soil crusts communities in mesic temperate soils. Microbial Ecology 51: 189-196. DOI: 10.1007/s00248-005-0121-3

Wang JN, Shi FS, Xu B, et al. (2014) Uptake and recovery of soil nitrogen by bryophytes and vascular plants in an alpine meadow. Journal of Mountain Science 11(2): 475-484. DOI: 10.1007/s11629-013-2707-4

West NE (1990) Structure and function of microphytic soil crusts in wildland ecosystems of arid to semi-arid regions. Advances in ecological research 20: 179-223. DOI: 10.1016/ Soo65-2504(08)60055-0

Zaady E, Gutterman Y, Boeken B (1997) The germination of mucilaginous seeds of Plantago coronopus, Reboudia pinnata, and Carrichtera annua on cyanobacterial soil crust from the Neger Desert. Plant Soil 190:247-252. DOI: 10.1023/ A:1004269031844

Zhang YM, Belnap J (2015) Growth responses of five desert plants as influenced by biological soil crusts from a temperate desert, China. Ecological Research 30(6): 1037-1045. DOI: 10.1007/s11284-015-1305-Z

Zellman KL (2012) Vegetation and biological soil crust succession on the sand dunes of San Miguel Island, Channel Islands National Park, California. Ph.D thesis, Colorado State University, CO, USA. 